\begin{tabular}{|l|l|}
\hline Postprint Version & 1.0 \\
\hline Journal website & $\underline{\mathrm{http}: / / \mathrm{dx} . \text { doi.org/10.1016/j.ijnurstu.2010.06.007 }}$ \\
\hline Pubmed link & $\underline{\mathrm{http} / / \text { www.ncbi.nlm.nih.gov/pubmed/20619411 }}$ \\
\hline DOI & $10.1016 /$ j.ijnurstu.2010.06.007 \\
\hline
\end{tabular}

This is a NIVEL certified Post Print, more info at http://www.nivel.eu

\title{
The introduction of a nursing guideline on depression at psychogeriatric nursing home wards: Effects on Certified Nurse Assistants
}

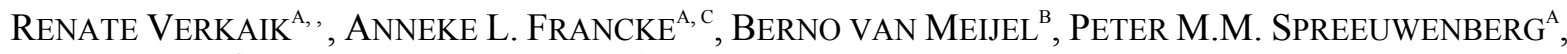 \\ MIEL W. RIBBE ${ }^{\mathrm{C}}$ AND JOZIEN M. BENSING ${ }^{\mathrm{A}}$ \\ ${ }^{a}$ NIVEL, Netherlands Institute for Health Services Research, Utrecht, The Netherlands \\ b INHolland University for Applied Sciences, Research Group Mental Health Nursing, Amsterdam, The \\ Netherlands \\ ${ }^{c}$ VU University Medical Center/EMGO Institute, Amsterdam, The Netherlands
}

\begin{abstract}
Background: To improve care for residents with depression in dementia, an evidence based nursing guideline was developed. Using the guideline has already shown positive effects on depression in psychogeriatric nursing home residents.

Objective: To study the effects of the introduction of the nursing guideline 'depression in dementia' on perceived professional autonomy, workload and feelings of powerlessness and confidence in Certified Nurse Assistants.

Design: A multi-center controlled intervention study with randomization at ward level, using pre-test, post-test and follow-up measurements.

Setting: 18 psychogeriatric wards in 9 Dutch nursing homes.

Participants: : 193 Certified Nurse Assistants working on psychogeriatric nursing home wards for at least $20 \mathrm{~h}$ per week.

Methods: An evidence based guideline for nursing teams of psychogeriatric nursing home wards was introduced on nine experimental wards to reduce depression in residents diagnosed with depression in dementia. The guideline introduction consisted of team training and the installation of a promotion group. The nine control wards continued providing usual care. Primary outcomes are: (1) perceived professional autonomy and (2) experienced workload in Certified Nurse Assistants measured with the VBBA subscales 'autonomy' and 'pace and amount of work'. Secondary outcomes are perceived powerlessness and confidence in caring for depressed and demented residents, using two self-developed scales.

Results: The guideline introduction had a small, significant, positive effect on generally perceived professional autonomy in the Certified Nurse Assistants of the experimental wards. No short-term effects were found on generally experienced workload, or on confidence and powerlessness in caring for depressed residents with dementia.

Conclusion: The introduction of the nursing guideline 'depression in dementia' has small, positive effects on perceived professional autonomy among the Certified Nurse Assistants. Long-term effects on experienced workload should be studied.
\end{abstract}


Verkaik, R., Francke, A.L., Meijel, B. van, Spreeuwenberg, P.M.M., Ribbe, M.W., Bensing, J.M. The introduction of a nursing guideline on depression at psychogeriatric nursing home wards: effects on Certified Nurse Assistants. International Journal of Nursing Studies: 2011, 48(6), 710-719

\section{INTRODUCTION}

\subsection{Background}

Caring for people with dementia is complex and demanding. On psychogeriatric nursing home wards in the Netherlands, about $85 \%$ of the residents are diagnosed with a dementia syndrome ([Ribbe et al., 1995] and [Schols et al., 2004]). Much of the care on these psychogeriatric wards is provided by Certified Nurse Assistants (CNAs). About $30 \%$ of these CNAs often experience feelings of powerlessness and lack of confidence in caring for their residents (Kerkstra and Van Bilsen, 1999). One of the important sources of this problem appears to lie in the patients' comorbid depressive behaviors ([Hallberg and Norberg, 1993] and [Kerkstra and Van Bilsen, 1999]). A study by Edberg et al. (2008) gives a plausible explanation for this with regard to nurses: they desire to do their best for the people in their care by trying to alleviate their suffering and enhance their quality of life. When they do not have the ability to do so, it causes strain. In the case of depression in dementia, CNAs may lack the necessary ability for several reasons.

In the first place, CNAs are generally not trained to support people with depression in dementia. Many people with dementia get into a negative depression cycle, because the balance between positive and negative experiences gets disturbed. By increasing positive experiences and decreasing negative ones, one can interrupt the negative depression cycle. Breaking through the depression of nursing home residents with dementia is difficult, but becomes even harder without specific training. For instance, one needs to know how to develop individualized care plans that take into account physical and cognitive limitations, abilities and preferences, using a step-by-step approach ([Teri et al., 1991] and [Teri, 1994]). In the Netherlands CNAs get about 3 years of basic general nursing training, but without specific attention to the support of people with depression in dementia.

Secondly, related to this lack of specific education, CNAs often have insufficient professional autonomy with regard to cases of depression in dementia. A lack of professional autonomy is reflected in the fact that CNAs, as a rule, do not develop psychosocial care plans themselves. This is usually done by psychologists attached to the nursing homes. Although most psychologists involve the CNAs in the development and application of psychosocial care plans, CNAs have stated during interviews, that they would prefer greater professional autonomy in this respect (not published material).

Thirdly, CNAs on psychogeriatric nursing home wards often experience high workload. High experienced workload is influenced by a concrete high task load containing, for example, a large percentage of physical care (van den Tooren and de Jonge, 2008) and household activities. ADL (activities of daily living) for nursing home residents with BPSD, like depression, often takes more time than normal because some residents may offer resistance to the care they receive (Buhr and White, 2006). CNAs spend as much as $40 \%$ of their time managing challenging behaviors (Cassidy and Sheikh, 2002). Besides, many Dutch nursing homes have a high workload, partly caused by difficulties with the recruitment of sufficient staff (Hoek et al., 2000). Experienced workload may also be affected by more subjective factors like perceived professional autonomy (te Boekhorst et al., 2008) as well as feelings of powerlessness and lack of confidence in caring for demented residents ([Kerkstra and Van Bilsen, 1999] and [Edberg et al., 2008]).

\subsection{Nursing guideline}

In order to help CNAs in supporting residents with depression in dementia, a nursing guideline was developed. The guideline was approved by the Dutch Nurses' Association (V\&VN) (NIVEL, Waerthove, 2004). The primary aim of the guideline was to reduce depression in demented nursing home residents. The secondary aim was to support CNAs in their care for depressed residents with dementia. The guideline was based on the so-called BehaviorTherapy-PleasantEvents, which Teri et al. (1997) showed to be effective in reducing depression in home dwelling people with dementia. The main principles of the method are (1) inducing individualized pleasant activities, and (2) reducing unpleasant events. The method is based on the Integrative Theory of Depression and Activity Schedules as developed and studied by Lewinsohn et al. (1985) and is also often applied and has proved effective in a non-demented population with depression (Cuijpers et al., 2007). In the method developed by (Teri et al., 1991) and (Teri et al., 1997) and Teri (1994) the primary relative of the demented person learned from a geriatrician how to develop and apply a socalled individualized Pleasant-Activities-Plan to their demented and depressed relative.

We adapted Teri's method in such a way that the CNAs of the depressed and demented residents were accorded the central role in developing and coordinating the application of the Pleasant-Activities-Plans. It was hoped to thus increase the CNAs' professional autonomy. Steps in the development of the Pleasant- 
Activities-Plans include, for instance, observing residents' depressive complaints, and assembling life history and specific information about preferred and disliked activities. In this regard CNAs have to collaborate with non-Certified Nurse Assistants from the nursing team and with other disciplines (physicians, psychologists, occupational therapists). A person-centered and systematic way of working forms the general framework of the guideline.

\subsection{Effect study}

The first aim of the trial into the effects of the nursing guideline 'Depression in dementia' was assessing the effects on depressed and demented residents. A second aim was assessing the effects on CNAs of the depressed and demented residents. For these purposes a multi-center controlled clinical trial at psychogeriatric nursing home wards was conducted. Another paper describes how the guideline introduction does significantly reduce depression in psychogeriatric nursing home residents with dementia (Verkaik et al., in press). The current paper describes the effects of the guideline introduction on perceived daily professional autonomy and workload of CNAs, and on feelings of powerlessness and confidence in caring for depressed and demented residents. Detailed information about the guideline and its introduction is contained in Fig. 1.

\section{[FIGURE 1]}

\subsection{Research model}

The research model we used in this part of the study was inspired by the Job-Demand-Control model (Karasek, 1979). In a recent publication, te Boekhorst et al., 2008, showed that this model very well describes the mechanisms of increased autonomy and decreased workload among CNAs working on nursing home wards. Fig. 2 describes the research model of this paper.

\section{[FIGURE 2]}

We expected that the introduction of the guideline would increase perceived daily professional autonomy in CNAs, because the guideline makes them the central person for developing and coordinating the application of the psychosocial support for residents with depression in dementia. We also expected that experienced workload would decrease in the long term because (a) residents get less depressed (Verkaik et al., in press) and will therefore cooperate better and/or show less resistance, and (b) because the guideline introduction will decrease perceived powerlessness and increase perceived confidence among CNAs when caring for residents with depression in dementia. In the shorter term, however, workload might increase because of the additional tasks and time the guideline introduction requires. Perceived professional autonomy and workload were in the original Job-Demand-Control model and are final outcomes. Therefore they were taken as primary outcomes of the study. Perceived powerlessness and confidence were added to the original model and were expected to have intermediate effects on professional autonomy and workload. They were therefore taken as secondary outcomes. The expectation is that if perceived-confidence increases and/or perceived powerlessness decreases, CNAs experience that they have more tools to help their residents, which enhances perceived professional autonomy and/or decreases experienced workload. The research questions of this paper are:

1. What are the effects of introducing the nursing guideline 'depression in dementia' on perceived professional autonomy and experienced workload of CNAs working on psychogeriatric nursing home wards?

2. What are the effects of the guideline introduction on CNAs' perceived powerlessness and confidence in supporting residents with depression in dementia?

\section{METHODS}

\subsection{Design}

The study is a multi-center controlled intervention study with randomization at ward level. The study was performed on 18 psychogeriatric wards of nine Dutch nursing homes. Each nursing home provided an experimental and a control ward. On the nine experimental wards the nursing guideline was introduced. On 
Verkaik, R., Francke, A.L., Meijel, B. van, Spreeuwenberg, P.M.M., Ribbe, M.W., Bensing, J.M. The introduction of a nursing guideline on depression at psychogeriatric nursing home wards: effects on Certified Nurse Assistants. International Journal of Nursing Studies: 2011, 48(6), 710-719

the nine control wards usual care continued. The introduction period lasted 11 weeks per ward. There were three measurement occasions:

(1) pre-test (before the guideline introduction);

(2) post-test (directly after the introduction period of 11 weeks);

(3) follow-up (10 weeks after the introduction period).

Data collection from pre-test to follow-up started in November 2005 in the first nursing home, and finished in May 2007 in the ninth. The study was approved by the Dutch Central Committee on Research involving Human Subjects (CCMO).

\subsection{Conditions}

In each nursing home the two participating wards were randomly assigned to one of two conditions (1) 'usual care' (no intervention), or (2) 'introduction of the guideline', in addition to usual care (intervention). The rationale for adopting cluster randomisation was that the guideline 'Depression in dementia' was developed for complete nursing teams working together around depressed and demented residents. An independent employee at the NIVEL institute was assigned to draw lots from a sealed envelope to establish on which ward of each nursing home 'the introduction of the guideline' would take place. Fig. 1 describes the content of the guideline introduction. The CNAs on the control wards were kept blind for the content of the guideline. The CNAs on the experimental wards signed an agreement that they would not talk to the caregivers on the control wards about the content of the guideline and the training they received. In the same contract they agreed not to work on each other's wards during the period the experiment took place.

\subsection{Setting}

In the Netherlands there are about 27 nursing home beds per 1000 inhabitants of 65 years of age and over. About $55 \%$ of these beds are situated in psychogeriatric wards for patients with dementia and $45 \%$ in somatic wards, primarily for patients with somatic problems (RIVM, 2003). Most of the about 340 Dutch nursing homes $(73 \%)$ have psychogeriatric wards as well as somatic wards (Schols et al., 2004). Psychogeriatric wards are separate wards or units in nursing homes for psychogeriatric residents, characterized by corridors, colors, and closed-door systems, that are adapted for these residents. They are comparable with specialized Alzheimer units in the United States. Of the residents 85\% is diagnosed with a dementia syndrome, mostly moderate to severe (GDS stages 5-7) (Zuidema et al., 2007). Daily nursing care is mainly delivered by Certified Nurse Assistants (CNAs) who in the Netherlands generally have 3 years of basic nursing training, and who are - regarding educational level and skills - rather comparable with Licensed Practical Nurses in the United States. The nursing home physician has main responsibility for medical care. In the Netherlands the nursing home physician is a formally recognized medical specialization, with 2 years of postgraduate university training in nursing home medicine. CNAs and nursing home physicians are supported by a team of psychologists, activity therapists, social workers, and others who are specifically educated for working in the nursing home context (Schols et al., 2004).

The participating nursing homes had applied in response to an invitation letter that was sent to 109 nursing homes in the central and western part of the Netherlands. The participating homes were the first nine which applied and also met the following eligibility criteria:

(1) A minimum of two nursing teams working on two separate but comparable psychogeriatric wards.

(2) The nursing teams did not work on each other's wards.

(3) The nursing teams were not yet applying any systematic methods that are comparable to the content of the guideline.

(4) No reorganizations or other interventions had been planned for the wards that might interfere with the introduction of the guideline.

Recruitment of the nine participating nursing homes took place between May and November 2005.

\subsection{Participants}

\subsubsection{CNAS}

Complete nursing teams participated in the current study. Exclusion criteria for individual caregivers were: (1) not certified or not registered; (2) employed for less than $20 \mathrm{~h}$ per week. On the 18 nursing home wards, 223 nurse assistants met these inclusion criteria. The background characteristics of the 193 CNAs who participated are provided in the results section and in Table 1. 
Verkaik, R., Francke, A.L., Meijel, B. van, Spreeuwenberg, P.M.M., Ribbe, M.W., Bensing, J.M. The introduction of a nursing guideline on depression at psychogeriatric nursing home wards: effects on Certified Nurse Assistants. International Journal of Nursing Studies: 2011, 48(6), 710-719

\section{[TABLE 1]}

\subsubsection{Residents}

All residents of the 18 participating wards $(n=598)$ were screened for depression in dementia. The details of the diagnostic procedure have been described elsewhere (Verkaik et al., 2009).

Nursing home physicians or psychologists in each nursing home determined the presence of dementia on basis of the DSM-IV-pc (American Psychiatric Association, 1996) and a diagnosis of depression in dementia was made with the provisional Diagnostic Criteria for Depression Of Alzheimer Disease (PDCdAD: Olin et al., 2002). In addition, dementia severity (Global Deterioration Scale: Reisberg et al., 1982) was established. Residents with severe dementia (Global Deterioration Scale stage 7) were excluded from the study because the intervention was aimed at residents who were still able to communicate verbally. The mean age of the residents was 83.7 (SD 7.2), 18\% were male $(n=17), 32 \%(n=31)$ had moderate dementia (GDS 5) and $41 \%(n=40)$ moderately severe dementia (GDS 6). There were no significant differences between the experimental and control groups regarding background characteristics.

\subsubsection{Sample size}

Because the first objective of the trial was measuring effects of the guideline introduction on depression in demented residents, the sample size was calculated based on the expected effects in the sample of residents and not CNAs.

\subsection{Outcome measures}

\subsubsection{Primary outcomes}

Perceived autonomy of the CNAs in their daily work was measured with the subscale 'autonomy' $(\alpha=.88 ; 11$ items) from the questionnaire 'Experience and Assessment of Work' (VBBA) by van Veldhoven and Meijman (1994). The VVBA scales are the most reliable, valid and sensitive scales available in Dutch for measuring work related outcomes. Examples of items in the autonomy subscale are: 'Do you have freedom in carrying out your daily activities?', 'Can you influence the planning of your activities?', and 'Do you solve problems yourself?'. Response categories are 'always', 'often', 'sometimes', and 'never'.

Experienced workload was measured with the subscale 'pace and amount of work' ( $\alpha=.76 ; 11$ items) from the questionnaire 'Experience and Assessment of Work' (VBBA) by van Veldhoven and Meijman (1994). Some items from the subscale 'pace and amount of work' are, for example 'Do you have too much work to do?', 'Do you experience problems with the work pace?', and 'Do you have to hurry?'.

\subsubsection{Secondary outcomes}

As secondary outcomes, CNAs' perceived powerlessness and perceived confidence in supporting residents with depression in dementia were assessed. Both variables were measured on a self-developed 5-point Likert scale, with the response categories 'completely disagree', 'partly disagree', 'do not disagree/do not agree', 'partly agree', 'completely agree' regarding the following statements:

'I feel confident/powerless in caring for $<$ name of specific resident diagnosed with depression in dementia'>, and

'In general I feel confident/powerless in caring for residents with dementia who are depressed', and

'In general I feel confident/powerless in caring for residents with dementia'.

Using data of the 193 CNAs participating in the current study a factor analysis was conducted to construct two scales: a confidence scale and a powerlessness scale, each consisting of three items. In the confidence scale $70 \%$ of the total variance was explained by a one-factor solution. In the powerlessness scale this was $63 \%$. Internal consistency of both scales was good (Cronbach's alpha $=.78$ for the confidence scale; .70 for the powerlessness scale).

\subsection{Control measures}

Control variables (covariates) for all primary and secondary outcomes are CNAs' age, gender, educational level, hours of employment per week and working fixed or flexible shifts. The scores on the two items of the perceived-confidence scale regarding the care for specific residents were corrected for duration of 
residence in the nursing home, care dependency ([Dijkstra et al., 1996] and [Dijkstra et al., 1999]), cognitive impairment.Morris et al., 1994), and medication use (antidepressants, antipsychotics, benzodiazepines and ACE-inhibitor/beta-blockers) during the study period, as reported by the nursing homes' pharmacists.

\subsection{Data collection}

Questionnaires were used for data collection of primary and secondary outcomes and background characteristics of the CNAs. Before the first questionnaire was distributed every participating CNA received a unique code, consisting of the first two characters of the ward name followed by a number. Researchers at the NIVEL institute (first and second author) were the only persons having access to the codes. The questionnaires containing the unique codes were sent to the CNAs in sealed envelopes. After completing the questionnaires CNAs posted them back to the NIVEL institute. To enhance the response rate, CNAs received a gift voucher for each of the three completed and returned questionnaires.

\subsection{Statistical methods}

Multilevel Repeated Measures Analysis was used for analyzing the data, using MLwiN-software (Rasbash et al., 2000). Four different levels of analysis were distinguished in the model: (1) measurement; (2) CNA; (3) ward; (4) nursing home. The multilevel model takes into account all available data yielding outcome measures in an adequate way: the paired samples of CNAs that have completed and returned all three or two of the tests (pre-test and post-test) as well as the unpaired pre-measurement data of those CNAs that only have pre-test data. The correlated paired measurements are controlled for by modeling the covariance between the measurements at the CNAs' level ([Bryk and Raudenbusch, 1992] and [Goldstein, 1995]).

The multilevel model cannot be applied to CNAs for whom not all covariate data are complete. These cases $(n=13)$ were excluded from the analyses. Data of the CNAs with complete covariate data $(n=180)$ were analyzed using the intention-to-treat principle: all participants were analyzed according to group assignment. For all outcome measures on pre-test, post-test and follow-up, adjusted estimated means and standard errors were calculated for the experimental and control groups, corrected for the control variables. To compare differences in trends (linear or quadratic) from pre-test to follow-up between the experimental and the control groups, Wald contrast tests $(\mathrm{H} 0$ : trend(experimental) - trend(control) $=0)$ were used. Trends were considered to differ significantly if the test score Chi-square was $=3.84(p \leq .05)$. This is similar to MANOVA repeated measures approach. An advantage of multilevel repeated measures is that an individual patient can have missing measurements on one of the three occasions. Linear and quadratic differences were both calculated because it is possible that the effects of the guideline introduction are larger immediately after the intervention (post-test) than at follow-up.

\section{RESULTS}

\subsection{Participants}

As described, all 223 Certified Nurse Assistants working $20 \mathrm{~h}$ or more were invited to participate in the study (109 on the experimental wards; 114 on the control wards). In total 193 CNAs were included in the study: 98 on the experimental wards and 95 on the control wards. For the experimental wards, we were able to discern the reasons for non-participation: maternity leave $(n=1)$, illness $(n=1)$, vacation $(n=1)$, only working in night shift $(n=3)$, conflict with the team manager $(n=1)$ and changing jobs $(n=4)$. We do not have information about reasons for non-participation on the control wards.

The response of the participating CNAs was rather high across the three measurement times: at pre-test $84 \%$ ( $n=163)$ of the CNAs responded ( 83 on the experimental wards; 80 on the control wards), at post-test $82 \%(n=159)$ ( 76 on the experimental wards; 83 on the control wards) and at follow-up $81 \%(n=156)$ of the CNAs responded (76 on the experimental wards; 80 on the control wards). Table 1 presents the background characteristics of the CNAs at pre-test, post-test and follow-up. The table shows that the experimental and control groups were to large extent comparable on background characteristics. To test the differences in background characteristics, $t$-tests and Chi-square analyses were used. There were no significant differences between the experimental and control group at pre-test, post-test and follow-up, or between measures within the experimental group or the control group $(p \geq .05)$. 
Verkaik, R., Francke, A.L., Meijel, B. van, Spreeuwenberg, P.M.M., Ribbe, M.W., Bensing, J.M. The introduction of a nursing guideline on depression at psychogeriatric nursing home wards: effects on Certified Nurse Assistants. International Journal of Nursing Studies: 2011, 48(6), 710-719

\subsection{Success of the guideline introduction}

For 39 of the 65 residents $(60 \%)$ who participated in the experimental group a Pleasant-Activities-Plan was developed and inserted into the residents care file. For the other 26 participating residents a PleasantActivities-Plan was also developed but not entered into the files. This provides an indication of the success of the guideline introduction. Analyses for another paper showed that at three wards the guideline introduction was successful, at four wards it was moderately successful and at two wards not successful. At all six moderately and not-successful wards CNAs stated that the actual use of the guideline was inhibited by reorganizations, few personnel, other training courses at the time of the guideline introduction or limited support from the team manager and/or higher management. In addition, at all nine wards CNAs stated that involving the non-Certified Nurse Assistants and nursing aides in the guideline introduction would likely have improved the guideline application.

\subsection{Primary outcomes: perceived professional autonomy and workload}

Table 2 provides the adjusted estimated means and standard errors for the experimental and control groups for all outcome measures on pre-test, post-test and follow-up. The table also shows Chi-square values that indicate whether trends in the experimental and control groups differ significantly $(p \leq .05)$ in a linear or quadratic way. Analyses showed no significant differences between nursing homes in any of the outcomes $(p>.05)$.

\section{[TABLE 2]}

\subsection{Perceived autonomy}

There is a significant, positive effect (linear) of the guideline introduction on the perceived professional autonomy of CNAs (see Table 2). A decrease on the VBBA-autonomy subscale means an increase in feelings of autonomy. In the experimental group the mean perceived professional autonomy first slightly decreases from pre-test to post-test, and then increases at follow-up to a higher level than at pre-test. In the control group, perceived daily professional autonomy declines from pre-test to follow-up. The trends in autonomy scores from pre-test to follow-up in both the experimental and control group were significant $(p \leq .05)$. Chi-square (quadratic) was 3.92 in the experimental group and 8.56 (linear) in the control group.

\subsection{Experienced workload}

No significant effect of the guideline introduction was found on experienced workload of the CNAs (see Table 2). In the experimental group experienced workload first decreased from pre-test to post-test and then increased at follow-up. In the control group experienced workload remained stable from pre-test to post-test and then increased at follow-up.

\subsection{Secondary outcome: perceived powerlessness and confidence}

No significant differences between the experimental and control groups were found on the variable 'perceived powerlessness' in caring for residents with depression in dementia (see Table 2). In the experimental group perceived powerlessness remained stable from pre-test to follow-up. In the control group perceived powerlessness decreased slightly from pre-test to follow-up.

Also no significant differences were found on the variable 'perceived confidence' (see Table 2). In the experimental as well as in the control group perceived confidence first increased from pre-test to post-test and then decreased somewhat at follow-up. In the control group the same trend can be observed.

\section{DISCUSSION}

As expected, significant, positive effects of the guideline introduction were found on perceived professional autonomy. However, contrary to expectations, no significant effects on experienced workload, powerlessness or confidence in caring for depressed and demented residents were found.

\subsection{Effects on autonomy}

Although the effect of the guideline introduction on professional autonomy was statistically significant, the increase of autonomy in the experimental group from pre-test to follow-up seems rather small: about 1 point on a scale from 0 to 100 . A likely explanation for the limited effect is that the guideline only concerned about $20 \%$ of the residents of a ward ([Zuidema et al., 2007] and [Verkaik et al., 2009]), while 
Verkaik, R., Francke, A.L., Meijel, B. van, Spreeuwenberg, P.M.M., Ribbe, M.W., Bensing, J.M. The introduction of a nursing guideline on depression at psychogeriatric nursing home wards: effects on Certified Nurse Assistants. International Journal of Nursing Studies: 2011, 48(6), 710-719

the scale used measured effects on the general professional autonomy that CNAs experience. The limited effect may also be related to the limited compliance with the guideline at some of the wards.

The calculated size of the effect is at least moderate, with a standardized difference of +2.12 at pre-test and a standardized difference of -0.62 at follow-up (Cohen, 2008).

The circumstance that in the experimental group the perceived autonomy firstly decreased from pre-test to post-test, and then increases can possibly explained by the fact that at first CNAs need help from relatives, occupational therapists, psychologists and others before they can start and apply the Pleasant-ActivitiesPlans. The observation that perceived autonomy decreased in the control group from pre-test to follow-up could possibly be caused by the fact that CNAs knew about the diagnosed depression in their residents, but did not get any methods that they could use to intervene into the depression themselves.

The positive effect, although small, fits however with the finding of Hoogeveen and Smith (1998) that CNAs are stimulated in their job if they themselves can find solutions for behavioral and psychological problems in dementia. As described in the introduction to this paper, before the guideline was introduced psychosocial care plans were mostly developed by psychologists, with generally only a consultation role for CNAs. The guideline introduction redefined these roles. It is important to observe that the CNAs favored this redefinition, but (still) really appreciated and needed consultation with psychologists, especially in cases of multiple behavioral or psychological disturbances (Verkaik et al., in press).

\subsection{Effects on workload}

As we have said, no significant differences were found between the experimental and control groups regarding general, experienced workload. Also in this regard it must be emphasized that the guideline only concerns about $20 \%$ of the residents of a psychogeriatric ward, whereas the instrument measured an aspect of the general work experience. Another explanation for the lack of effects on workload is that it probably takes more time to see such effects of the guideline introduction. At post-test and even at follow-up the guideline introduction had just finished and CNAs had yet to integrate the application of the plans into their routines.

However, it may be interpreted as a positive finding that the guideline introduction did not actually increase the experienced workload particularly in the short term, as the introduction incurred additional tasks for the CNAs.

\subsection{Effects on powerlessness and confidence}

The fact that we did not establish statistically significant effects on perceived powerlessness and confidence was contrary to our expectations. We also have no explanation for the observation that perceived powerlessness and confidence are not influenced in the experimental group and, although not statistically significant, show a slight decrease in the control group.

This points in the direction of measurement problems. We had to use self-developed scales, since no suitable, validated scales were available from earlier studies ([Hallberg and Norberg, 1993] and [Kerkstra and Van Bilsen, 1999]). It is possible that our scales did not significantly or adequately measure the complex concepts of powerlessness and confidence. More research into the complex concepts perceived powerlessness and confidence is needed. Another possibility is of course that there were no actual effects on powerlessness or confidence, and that the introduction of the guideline was not successful in this regard. However, in personal interviews with CNAs we did get the impression that they felt more confident and less powerless in caring for this target group.

\subsection{Study limitations}

The first limitation of this study was that the CNAs on the control wards knew which residents were diagnosed with depression in dementia. It is possible that knowing which residents were depressed without getting methods to help residents induced a decrease of perceived autonomy. Also the CNAs were interviewed about the depressive symptoms of these residents at pre-test, post-test and follow-up. It might be possible that this influenced their perceived professional autonomy, workload, confidence and powerlessness.

A second limitation is that the participating nursing homes themselves applied for participation, meaning that they may possibly have had a more positive attitude towards the nursing guideline 'Depression in Dementia' than an average nursing home. It is also possible that the workload on the participating wards 
Verkaik, R., Francke, A.L., Meijel, B. van, Spreeuwenberg, P.M.M., Ribbe, M.W., Bensing, J.M. The introduction of a nursing guideline on depression at psychogeriatric nursing home wards: effects on Certified Nurse Assistants. International Journal of Nursing Studies: 2011, 48(6), 710-719

was less high than average, or that the CNAs experienced more problems in supporting residents with depression in dementia. These factors could affect the generalizability of the results.

With respect to international generalizability, we are aware that in most other countries the role and educational level of CNAs on psychogeriatric wards is somewhat different to the situation in the Netherlands. In the United States, for example, CNAs are not trained in developing care plans.

Accordingly, the division of tasks in the guideline could be rearranged according to the specific situation. Licensed Practical Nurses (LPNs) could, for example, be in charge of developing the Pleasant-ActivitiesPlans, leaving the CNAs to carry them out. Research should be conducted to establish whether the effects on perceived autonomy and powerlessness in these cases are comparable.

\section{CONCLUSIONS}

The introduction of the nursing guideline 'depression in dementia' on psychogeriatric nursing home wards did have a positive, though small, significant effect on the perceived professional autonomy of CNAs. Effects could probably be enlarged if non-Certified Nurse Assistants and nursing helpers are also trained, and managers pay more attention to the necessary conditions for successful introduction. We did not find any short-term effects on experienced workload, powerlessness and confidence. In all likelihood, in the long term, when the guideline is consolidated, positive effects on workload may also be shown. Conflict of interest. There are no conflicts of interest.

Funding. This study was funded by ZonMw, the Netherlands Organization for Health Research and Development (project no. 5401.0001).

Ethical approval. The study was approved by the Dutch Central Committee on Research involving Human Subjects (CCMO: P04.1658).

\section{REFERENCES}

American Psychiatric Association, 1996 American Psychiatric Association, DSM-IV patiëntenzorg: diagnostiek en classificatie van psychische stoornissen voor de geneeskunde, Diagnostic and Statistical Manual of Mental Disorders (fourth ed., Primary Care), Swets \& Zeitlinger, Lisse (1996).

Bryk and Raudenbusch, 1992 A.S. Bryk and S.W. Raudenbusch, Hierarchical Linear Models: Applications and Data Management Methods, Sage Publications, Newbury Park (1992).

Buhr and White, 2006 G.T. Buhr and H.K. White, Difficult behaviors in long-term care patients with dementia, J. Am. Med. Dir. Assoc. 7 (2006), pp. 180-192.

Cassidy and Sheikh, 2002 E.L. Cassidy and J.I. Sheikh, Pre-intervention assessment for disruptive behavior problems: a focus on staff needs, Aging Ment. Health 6 (2002), pp. 166-171.

Cohen, 2008 J. Cohen, A power primer, Psychol. Bull. 112 (2008), pp. 155-159.

Cuijpers et al., 2007 P. Cuijpers, A. van Straten and L. Warmerdam, Behavioral activation treatments of depression: a meta-analysis, Clin. Psychol. Rev. 27 (2007), pp. 318-326.

Dijkstra et al., 1996 A. Dijkstra, G. Buist and T. Dassen, Nursing-care dependency. Development of an assessment scale for demented and mentally handicapped patients, Scand. J. Caring Sci. 10 (1996), pp. 137-143.

Dijkstra et al., 1999 A. Dijkstra, G. Buist, P. Moorer and T. Dassen, Construct validity of the Nursing Care Dependency Scale, J. Clin. Nurs. 8 (1999), pp. 380-388.

Edberg et al., 2008 A.K. Edberg, M. Bird, D.A. Richards, R. Woods, P. Keeley and V. Davis-Quarrell, Strain in nursing care of people with dementia: nurses' experience in Australia, Sweden and United Kingdom, Aging Ment. Health 12 (2008), pp. 236-243.

Goldstein, 1995 H. Goldstein, Multilevel Statistical Models, Halsted Press, New York (1995).

Hallberg and Norberg, 1993 I.R. Hallberg and A. Norberg, Strain among nurses and their emotional reactions during 1 year of systematic clinical supervision combined with the implementation of individualized care in dementia nursing, J. Adv. Nurs. 18 (1993), pp. 1860-1875.

Hoek et al., 2000 J.F. Hoek, B.W. Penninx, G.J. Ligthart and M.W. Ribbe, Health care for older persons, a country profile: The Netherlands, J. Am. Geriatr. Soc. 48 (2000), pp. 214-217.

Hoogeveen and Smith, 1998 F.R. Hoogeveen and J. Smith, Preferenties van dementerende ouderen, Preferences of Elderly with Dementia. Utrecht (1998) NZI, publ.nr. 198.1198.

Karasek, 1979 R.A. Karasek, Job demands, job decision latitude, and mental strain: implications for job redesign, Admin. Sci. Quart. 24 (1979), pp. 285-307. 
Verkaik, R., Francke, A.L., Meijel, B. van, Spreeuwenberg, P.M.M., Ribbe, M.W., Bensing, J.M. The introduction of a nursing guideline on depression at psychogeriatric nursing home wards: effects on Certified Nurse Assistants. International Journal of Nursing Studies: 2011, 48(6), 710-719

Kerkstra and Van Bilsen, 1999 A. Kerkstra and P.M.A. Van Bilsen, Omgaan met dementerende bewoners voor verzorgenden in het verpleeghuis, How Caregivers in Nursing Homes Deal with Dementia Patients, NIVEL, Utrecht (1999).

Lewinsohn et al., 1985 P.M. Lewinsohn, H. Hoberman and L. Teri et al. In: S. Reiss and R. Bootzin, Editors, An Integrative Theory of Depression, Academic Press, New York (1985), pp. 331-359.

Morris et al., 1994 J.N. Morris, B.E. Fries, D.R. Mehr, C. Hawes, C. Philips, V. Mor and L.A. Lipsitz, MDS Cognitive Performance Scale, J. Gerontol. 20 (1994), pp. M174-182.

Olin et al., 2002 J.T. Olin, L.S. Schneider and I.R. Katz et al., Provisional diagnostic criteria for depression of Alzheimer disease, Am. J. Geriatr. Psychiatr. 10 (2002), pp. 125-128.

Rasbash et al., 2000 J. Rasbash, W. Browne and M. Healy, MlwiN (Version 1.10), Multilevel Models Project Institute of Education, London (2000).

Reisberg et al., 1982 B. Reisberg, S.H. Ferris, M.J. de Leon and T. Crook, The Global Deterioration Scale for assessment of primary degenerative dementia, Am. J. Psychiatr. 139 (1982), pp. 1136-1139.

Ribbe et al., 1995 M.W. Ribbe, J.Th. van Mens and D.H.M. Frijters, Kenmerken van patiënten tijdens verblijf in het verpleeghuis en bij ontslag, Patient characteristics during residence and admission from nursing homes, Ned Tijdschr Geneeskd 139 (1995), pp. 123-127.

Schols et al., 2004 J.M. Schols, H.F. Crebolder and C. van Weel, Nursing home and nursing home physician: the Dutch experience, J. Am. Med. Dir. Assoc. 5 (2004), pp. 207-212.

te Boekhorst et al., 2008 S. te Boekhorst, B. Willemse, M.F. Depla, J.A. Eefsting and A.M. Pot, Working in group living homes for older people with dementia: the effects on job satisfaction and burnout and the role of job characteristics, Int. Psychogeriatr. 20 (2008), pp. 927-940.

Teri et al., 1991 L. Teri, R. Logsdon and J. Uomoto, Treatment of Depression in Patients with Alzheimer's Disease. Therapist Manual and Caregiver Manual, University of Washington, Seattle, WA (1991).

Teri, $1994 \mathrm{~L}$. Teri, Behavioral treatment of depression in patients with dementia, Alzheimer Dis. Assoc. Disord. 8 (Suppl. 3) (1994), pp. 66-74. Teri et al., 1997 L. Teri, R.G. Logsdon, J. Uomoto and S.M. McCurry, Behavioral treatment of depression in dementia patients: a controlled clinical trial, J. Gerontol. B: Psychol. Sci. Soc. Sci. 52 (1997), pp. 159-166.

van den Tooren and de Jonge, $2008 \mathrm{M}$. van den Tooren and J. de Jonge, Managing job stress in nursing: what kind of resources do we need?, J. Adv. Nurs. 63 (2008), pp. 75-84.

van Veldhoven and Meijman, $1994 \mathrm{M}$. van Veldhoven and T. Meijman, Het meten van psychosociale arbeidsbelasting, The Measurement of Psychosocial Workload, NIA, Amsterdam (1994).

Waerthove, 2004 NIVEL, Waerthove, Het begeleiden van mensen met dementie die depressief zijn. Richtlijn voor verzorgenden, Supporting People with Dementia and Comorbid Depression. A Nursing Guideline, NIVEL, Utrecht (2004).

Verkaik et al., 2009 R. Verkaik, A.L. Francke, B. van Meijel, M.W. Ribbe and J.M. Bensing, Comorbid depression in dementia on psychogeriatric nursing home wards: which symptoms are prominent?, Am. J. Geriatr. Psychiatry 17 (2009), pp. 565-573.

Verkaik et al., in press Verkaik R., Francke A.L., van Meijel B., Spreeuwenberg P.M.M., Ribbe M.W., Bensing J.M., The effects of a nursing guideline on depression in psychogeriatric nursing home residents with dementia. Int. J. Geriatr. Psychiatry. in press.

Zuidema et al., 2007 S.U. Zuidema, E. Derksen, F.R. Verhey and R.T. Koopmans, Prevalence of neuropsychiatric symptoms in a large sample of Dutch nursing home patients with dementia, Int. J. Geriatr. Psychiatry 22 (2007), pp. 632-638. 
Verkaik, R., Francke, A.L., Meijel, B. van, Spreeuwenberg, P.M.M., Ribbe, M.W., Bensing, J.M. The introduction of a nursing guideline on depression at psychogeriatric nursing home wards: effects on Certified Nurse Assistants. International Journal of Nursing Studies: 2011, 48(6), 710-719

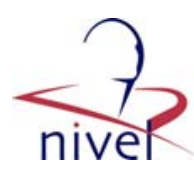

\section{TABLES}

Table 1. Background characteristics of participating CNAs.

\begin{tabular}{|c|c|c|c|c|c|c|}
\hline & \multicolumn{3}{|c|}{ Experimental group } & \multicolumn{3}{|c|}{ Control group } \\
\hline & $\begin{array}{l}\text { Pre-test } \\
(n=83)\end{array}$ & $\begin{array}{l}\text { Post-test } \\
(n=76)\end{array}$ & $\begin{array}{l}\text { Follow-up } \\
(n=76)\end{array}$ & $\begin{array}{l}\text { Pre-test } \\
(n=80)\end{array}$ & $\begin{array}{l}\text { Post-test } \\
(n=83)\end{array}$ & $\begin{array}{l}\text { Follow-up } \\
(n=80)\end{array}$ \\
\hline $\begin{array}{c}\text { Age, years } \\
(\text { mean } \pm \text { SD) }\end{array}$ & $37.8 \pm 9.8$ & $37.8 \pm 9.6$ & $38.8 \pm 9.9$ & $39.7 \pm 10.5$ & $39.2 \pm 10.2$ & $40.4 \pm 9.8$ \\
\hline Range & $20-58$ & $20-59$ & $20-59$ & $19-61$ & $20-62$ & $20-58$ \\
\hline Sex male, $n(\%)$ & $6(7.2)$ & $5(6.6)$ & $4(5.3)$ & $3(3.8)$ & $3(3.6)$ & $2(2.5)$ \\
\hline \multicolumn{7}{|c|}{ Highest educational degree, $n(\%)$} \\
\hline $\begin{array}{c}\text { Lower } \\
\text { vocational }\end{array}$ & $3(3.6)$ & $1(1.3)$ & $1(1.3)$ & $3(3.8)$ & $0(0.0)$ & $1(1.3)$ \\
\hline $\begin{array}{c}\text { Interm. } \\
\text { vocational }\end{array}$ & $65(78.3)$ & $61(80.3)$ & $56(73.7)$ & $60(75.0)$ & $68(81.9)$ & $66(82.5)$ \\
\hline $\begin{array}{c}\text { Higher } \\
\text { vocational }\end{array}$ & $7(8.4)$ & $5(6.6)$ & $10(13.2)$ & $6(7.5)$ & $6(7.2)$ & $6(7.5)$ \\
\hline Other & $8(9.6)$ & $9(11.8)$ & $8(10.5)$ & $11(13.8)$ & $9(10.8)$ & $8(8.8)$ \\
\hline $\begin{array}{l}\text { Hours employed } \\
\text { per week (mean } \\
\text { hours } \pm \mathrm{SD})\end{array}$ & $27.8 \pm 6.7$ & $27.1 \pm 6.8$ & $27.5 \pm 7.4$ & $27.2 \pm 6.8$ & $27.5 \pm 6.5$ & $27.0 \pm 6.5$ \\
\hline $\begin{array}{l}\text { Working fixed } \\
\text { shifts, } n(\%)\end{array}$ & $18(21.7)$ & $18(23.7)$ & $18(23.7)$ & $14(17.5)$ & $18(21.7)$ & $19(23.8)$ \\
\hline
\end{tabular}


Verkaik, R., Francke, A.L., Meijel, B. van, Spreeuwenberg, P.M.M., Ribbe, M.W., Bensing, J.M. The introduction of a nursing guideline on depression at psychogeriatric nursing home wards: effects on Certified Nurse Assistants. International Journal of Nursing Studies: 2011, 48(6), 710-719

Table 2. Differences in outcome trends between experimental and control groups.

\begin{tabular}{|c|c|c|c|c|c|c|c|c|}
\hline \multirow[t]{2}{*}{$\begin{array}{l}\text { Outcome } \\
\text { measures }\end{array}$} & \multicolumn{2}{|c|}{$\begin{array}{l}\text { Pre-test mean } \\
\text { (se) }\end{array}$} & \multicolumn{2}{|c|}{ Post-test mean (se) } & \multicolumn{2}{|c|}{$\begin{array}{l}\text { Follow-up } \\
\text { mean (se) }\end{array}$} & \multirow[t]{2}{*}{$\chi^{2}$-Linear } & \multirow[t]{2}{*}{$\chi^{2}$-Quadratic } \\
\hline & Exp. & Contr. & Exp. & Contr. & Exp. & $\begin{array}{l}\text { Con } \\
\text { tr. }\end{array}$ & & \\
\hline $\begin{array}{l}\text { Primary: } \\
\text { perceived } \\
\text { autonomy } \\
\text { (subscale } \\
\text { VBBA: } 0.00- \\
100.00 \text { ) }\end{array}$ & $\begin{array}{c}43.54 \\
(1.86)\end{array}$ & $\begin{array}{c}39.37 \\
(1.97)\end{array}$ & $\begin{array}{c}44.95 \\
(1.52)\end{array}$ & $41.16(1.93)$ & $\begin{array}{c}42.6 \\
(1.74)\end{array}$ & $\begin{array}{l}43.7 \\
2 \\
(1.80)\end{array}$ & $6.71^{*}$ & 1.61 \\
\hline \begin{tabular}{l}
\multicolumn{1}{l}{ Primary: } \\
experienced \\
workload \\
(subscale \\
VBBA: $0.00-$ \\
100.00 )
\end{tabular} & $\begin{array}{c}35.82 \\
(1.61)\end{array}$ & $\begin{array}{c}36.77 \\
(1.75)\end{array}$ & $\begin{array}{c}33.98 \\
(1.65)\end{array}$ & $\begin{array}{c}36.79 \\
(1.80)\end{array}$ & $\begin{array}{c}36.28 \\
(1.67)\end{array}$ & $\begin{array}{c}38.2 \\
(1.67)\end{array}$ & 0.39 & 1.15 \\
\hline $\begin{array}{l}\text { Secondary: } \\
\text { perceived } \\
\text { confidence (1- } \\
5)\end{array}$ & $\begin{array}{c}3.93 \\
(0.08)\end{array}$ & $\begin{array}{r}3.79 \\
(0.10)\end{array}$ & $\begin{array}{r}4.06 \\
(0.09)\end{array}$ & $3.96(0.09)$ & $\begin{array}{c}4.02 \\
(0.08)\end{array}$ & $\begin{array}{c}3.82 \\
(0.09)\end{array}$ & 0.19 & 0.40 \\
\hline $\begin{array}{l}\text { Secondary: } \\
\text { perceived } \\
\text { powerlessness } \\
(1-5)\end{array}$ & $\begin{array}{c}2.93 \\
(0.07)\end{array}$ & $\begin{array}{r}3.00 \\
(0.08)\end{array}$ & $\begin{array}{c}2.96 \\
(0.08)\end{array}$ & $3.05(0.09)$ & $\begin{array}{c}2.93 \\
(0.08)\end{array}$ & $\begin{array}{r}2.87 \\
(0.07)\end{array}$ & 1.06 & 0.50 \\
\hline
\end{tabular}

The underlined scores after the measures indicate the most favorable score for the scale. Mean $=$ estimated mean score (multilevel analysis); se $=$ standard error; $\chi^{2}=$ Chi-square (1 degree of freedom). ${ }^{*}$ Indicates a significantly different trend in the experimental and control groups from pre-test to follow-up in favor of the experimental group ( $p \leq .05$; Chi-square $>3.84,1$ degree of freedom). 
Verkaik, R., Francke, A.L., Meijel, B. van, Spreeuwenberg, P.M.M., Ribbe, M.W., Bensing, J.M. The introduction of a nursing guideline on depression at psychogeriatric nursing home wards: effects on Certified Nurse Assistants. International Journal of Nursing Studies: 2011, 48(6), 710-719

\section{FIGURES}

Fig. 1. Content of the guideline introduction.

\section{Content of the introduction of the nursing guideline on the wards}

\section{(1) Training and homework}

On each participating ward the training was provided by one of three trainers of the Centre for Training and Expertise Osira/Bernardus from Amsterdam. Although the training was focused on CNAs, the nursing team manager and occupational therapist were also invited to attend all three training sessions. This was considered important for adequate support for the CNAs in using the guideline. The course consisted of: three hours of training in week 1 (first training session); homework in week 2 and 3; three hours of training in week 4 (second training session); homework in weeks 5 to 10; a three hour follow-up training session in week 11 (follow-up training);

\section{First training session}

Core elements of the first training session, in line with the key elements of the guideline, were (1) how to increase individualized pleasant activities, and (2) how to decrease unpleasant events. Additionally, attention was paid to recognition of comorbid depression and dementia and the importance of a person centered and systematic way of working. At the end of the first training session CNAs learned which of their current residents were diagnosed by the nursing home physician or psychologist with depression in dementia. During the training session, groups of three to five CNAs were formed around each diagnosed resident. In the following weeks each group had to develop a PleasantActivities-Plan for their resident.

\section{Pleasant-Activities-Plans (homework)}

As a first step, data about the life history, personality and preferred and disliked activities were collected from the resident and his or her family. Information was also gathered about present depressive symptoms and the contexts in which these occur. Based on the collected information, the Pleasant-Activities-Plans had to contain written information on depression symptoms and the purposes, planning and evaluation of individualized and tailor-made pleasant activities. Activities in the plan could be conducted by CNAs themselves during regular care (e.g, play preferred music or make jokes during morning care) or during additional care (e.g. go outside into the garden). Activities could also be performed by occupational therapists or relatives of the resident (e.g. take the resident to a riding school if he loves horses or to the local pub), but the CNAs are responsible for developing, facilitating and evaluating the activities.

\section{$2^{\text {tid }}$ and follow-up training sessions}

In the second training session the formulated Pleasant-Activities-Plans were discussed in the group. After the necessary adaptations were made, the plans were integrated into daily care and evaluated as described in the plan. In the follow-up training the experiences of the CNAs were discussed for each participating resident and plans were made for further introduction of the guideline onto the ward.

\section{(2) Promotion group}

A "promotion group" consisting of the nursing team manager, occupational therapist and two CNAs was installed, with a view to encouraging and supporting the team in following the guideline. This group could consult the trainer between weeks 1 and 11 . 
Verkaik, R., Francke, A.L., Meijel, B. van, Spreeuwenberg, P.M.M., Ribbe, M.W., Bensing, J.M. The introduction of a nursing guideline on depression at psychogeriatric nursing home wards: effects on Certified Nurse Assistants. International Journal of Nursing Studies: 2011, 48(6), 710-719

Fig. 2. Job-Demand-Control model adapted to current study hypotheses.

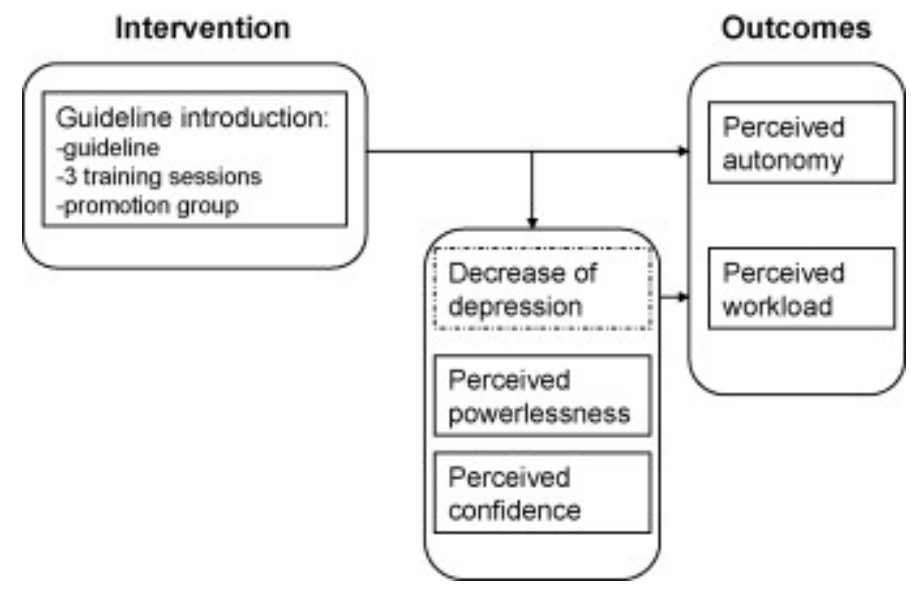

